\title{
A commentary on Diagnosing Cushing's disease in the context of renal failure
}

\author{
Hershel Raff1, Eric P Cohen ${ }^{2}$ and James W Findling ${ }^{3}$ \\ ${ }^{1}$ Departments of Medicine, Surgery, and Physiology, Medical College of Wisconsin and Endocrine Research \\ Laboratory, Aurora St Luke's Medical Center, Aurora Research Institute, Milwaukee, Wisconsin, USA, ${ }^{2}$ Nephrology \\ Division, Department of Medicine, University of Maryland School of Medicine, Baltimore, Maryland, USA, and \\ ${ }^{3}$ Endocrinology Center and Clinics, Medical College of Wisconsin, Menomonee Falls, Wisconsin, USA
}

Correspondence should be addressed to H Raff Email hraff@mcw.edu

\begin{abstract}
The diagnosis of endogenous hypercortisolism (Cushing's syndrome) is extremely challenging. Chronic kidney disease (CKD) increases the activity of the hypothalamic-pituitary-adrenal axis making the diagnosis of Cushing's syndrome even more challenging. This is particularly so since urine free cortisol (UFC) testing is not useful in CKD. The case report by Stroud et al. in this issue of the European Journal of Endocrinology highlights this problem by finding normal UFC in a patient with pituitary ACTH-dependent Cushing's syndrome. Elevated late-night salivary cortisol (LNSC) testing was diagnostic and pituitary adenomectomy was curative. LNSC measurement is the diagnostic test of choice in patients with suspected Cushing's syndrome, particularly in the presence of CKD..
\end{abstract}

The diagnosis of endogenous hypercortisolism (Cushing's syndrome) is one of the most difficult problems in endocrinology $(1,2)$. The signs and symptoms of Cushing's syndrome overlap with many common medical disorders such as obesity and the metabolic syndrome $(1,2,3)$. Another challenge to establishing a diagnosis of neoplastic/pathologic endogenous hypercortisolism is that many common disorders such as alcoholism and depression may cause a state of non-neoplastic/ physiologic hypercortisolism (formerly known as pseudoCushing's syndrome) and may lead to similar clinical and biochemical findings (3).

In this issue of the European Journal of Endocrinology, Stroud et al. present an interesting case of a patient with chronic kidney disease (CKD) 4/5 (4) (eGFR of $16 \mathrm{ml} / \mathrm{min}$ (reference range $(\mathrm{RR})>90$ )) and many of the stigmata of Cushing's syndrome (5). The patient had severe proteinuria $(3.3 \mathrm{~g} /$ day $(\mathrm{RR}<0.6))$ and a surprisingly normal urine output $(\sim 2 \mathrm{~L} /$ day with a urine creatinine excretion rate within the expected range). Urine free cortisol (24-h UFC) was within the reference range $(77-118 \mathrm{nmol} /$ day
(RR <250)). However, late-night salivary cortisol was increased $(20.0 \mathrm{nmol} / \mathrm{L}(\mathrm{RR}<8.0))$ and morning serum cortisol was not suppressed after a $1 \mathrm{mg}$ overnight dexamethasone suppression test (DST; $262 \mathrm{nmol} / \mathrm{L}$ (RR $<50)$ ) or $8 \mathrm{mg}$ DST $(153 \mathrm{nmol} / \mathrm{L})$ all of which made the diagnosis of Cushing syndrome extremely likely $(1,2)$. ACTH-dependent Cushing syndrome was established with an elevated plasma ACTH $(57 \mathrm{pmol} / \mathrm{L}(\mathrm{RR}<12)$ ). The patient had an ACTH-secreting pituitary adenoma (Cushing disease) removal of which led to a biochemical remission and improvement in blood pressure control.

The diagnostic problem in this patient highlights the increasing appreciation that severe CKD may often be associated with a state of non-neoplastic hypercortisolism accompanied by elevations of plasma ACTH and late-night serum and salivary cortisol as well as abnormal cortisol suppression after dexamethasone suppression $(6,7,8$, $9)$. The mechanism for the dysregulated cortisol excess in severe $\mathrm{CKD}$ is not a decrease in the renal clearance of cortisol, and correspondingly, the urine cortisol measurements are typically normal as in this patient (c) 2019 European Society of Endocrinology Printed in Great Britain
Published by Bioscientifica Ltd. 
(10). CKD seems to activate the hypothalamic-pituitaryadrenal axis presumably from a hypothalamic origin related to the stress and high inflammatory state resulting from CKD and chronic dialysis $(6,9)$. The diurnal nadir in serum cortisol is increased in severe $\mathrm{CKD}$, reflected by elevations in late-night salivary cortisol (LNSC) $(6,7)$. Furthermore, there is a positive correlation between disrupted cortisol circadian rhythm and elevations of serum C-reactive protein in patients with severe CKD (6). In addition, it has been known for decades that CKD patients have abnormal suppression of cortisol after lowdose dexamethasone (9). Initially, this was thought to be related to poor dexamethasone absorption, but the patient in this report had very adequate dexamethasone levels. The abnormal dexamethasone suppression in CKD may be related to several other factors including some degree of glucocorticoid resistance, the chronic inflammatory state, and the depression that may complicate the course of severe CKD that is apt to progress to true end-stage renal disease requiring renal replacement therapy $(3,4,6)$.

That this report claims to be the first patient with renal failure in whom corticotroph tumor removal cured Cushing's disease illustrates the difficulty in establishing the diagnosis of neoplastic hypercortisolism in CKD patients. The patient reported here had a large pituitary neoplasm in addition to a very persuasive clinical and biochemical profile. Of course, many patients with Cushing's disease do not have such an obvious clinical presentation $(1,2)$.

Even in patients with normal renal function, many have questioned the utility of measuring 24-h UFC to diagnose Cushing's disease particularly because of the large number of false negatives $(11,12)$. The measurement of UFC is also questionable considering the likelihood of altered steroid metabolism by severely diseased kidneys (10). It is fortunate in the case of this patient that the clinicians pursued the diagnosis of Cushing's syndrome on clinical grounds despite the normal UFC, and subsequently used the appropriate diagnostic tests.

The consideration of neoplastic hypercortisolism in CKD patients should follow the contemporary diagnostic guidelines (13): consistently normal LNSC will exclude the diagnosis. However, elevated LNSC and abnormal dexamethasone suppression must be viewed with caution. Although some patients with equivocal clinical or radiologic findings may require secondary diagnostic tests for neoplastic hypercortisolism such as the DDAVP stimulation test or the dexamethasone-CRH test (3); neither of these tests have been well studied in CKD patients. A higher than expected blood glucose or blood pressure may prompt further evaluation for Cushing's syndrome in a patient with severe CKD. Finally, there is no substitute for good clinical judgement and experience.

In conclusion, this case highlights that the measurement of LNSC, and perhaps the oDST, is the optimal approach to the diagnosis of Cushing's syndrome (1). A normal urine free cortisol is not useful to rule out Cushing's syndrome because of its poor sensitivity (12). As we have stated on many occasions, if you have never missed the diagnosis of Cushing's syndrome or been humbled by trying to establish its cause, you should refer your patients with suspected hypercortisolism to someone who has (2).

\section{Declaration of interest}

$\mathrm{H}$ R is a consultant for Cerium Pharmaceuticals and Corcept. E P C is a consultant for Fusion Pharmaceuticals and Octimet Oncology. J W F is a consultant and investigator for Novartis and Corcept.

\section{Funding}

This paper did not receive any specific grant from any funding agency in the public, commercial or not-for-profit sector.

\section{References}

1 Findling JW \& Raff H. Cushing's syndrome: important issues in diagnosis and management. Journal of Clinical Endocrinology and Metabolism 200691 3746-3753. (https://doi.org/10.1210/jc.2006-0997)

2 Findling JW \& Raff H. Diagnosis and differential diagnosis of Cushing's syndrome. Endocrinology and Metabolism Clinics of North America 200130 729-747. (https://doi.org/10.1016/S08898529(05)70209-7)

3 Findling JW \& Raff H. DIAGNOSIS of ENDOCRINE DISEASE: Differentiation of pathologic/neoplastic hypercortisolism (Cushing's syndrome) from physiologic/non-neoplastic hypercortisolism (formerly known as pseudo-Cushing's syndrome). European Journal of Endocrinology 2017176 R205-R216. (https://doi.org/10.1530/EJE-160946)

4 Levey AS, Eckardt KU, Tsukamoto Y, Levin A, Coresh J, Rossert J, De Zeeuw DDE, Hostetter TH, Lameire N \& Eknoyan G. Definition and classification of chronic kidney disease: a position statement from Kidney Disease: Improving Global Outcomes (KDIGO). Kidney International 200567 2089-2100. (https://doi.org/10.1111/j.15231755.2005.00365.x)

5 Stroud A, Zhang J \& McCormack A. Diagnosing Cushing's disease in the context of chronic kidney disease: a case report and literature review. European Journal of Endocrinology 2019181 K29-K35. (https://doi.org/10.1530/EJE-19-0326)

6 Raff H \& Trivedi H. Circadian rhythm of salivary cortisol, plasma cortisol, and plasma ACTH in end-stage renal disease. Endocrine Connections 20132 23-31. (https://doi.org/10.1530/EC-12-0058) 7 Cardoso EMdL, Arregger AL, Budd D, Zucchini AE \& Contreras LN. Dynamics of salivary cortisol in chronic kidney disease patients at stages 1 through 4. Clinical Endocrinology 201685 313-319. (https:// doi.org/10.1111/cen.13023)

8 Letizia C, Mazzaferro S, De Ciocchis A, Cerci S, Morabito S, Cinotti GA \& Scavo D. Effects of haemodialysis session on plasma beta-endorphin, ACTH and cortisol in patients with end-stage renal 
disease. Scandinavian Journal of Urology and Nephrology 199630 399-402. (https://doi.org/10.3109/00365599609181317)

9 Wallace EZ, Rosman P, Toshav N, Sacerdote A \& Balthazar A. Pituitary-adrenocortical function in chronic renal failure: studies of episodic secretion of cortisol and dexamethasone suppressibility. Journal of Clinical Endocrinology and Metabolism 198050 46-51. (https://doi.org/10.1210/jcem-50-1-46)

10 Sharp NA, Devlin JT \& Rimmer JM. Renal failure obfuscates the diagnosis of Cushing's disease. JAMA 1986256 2564-2565. (https:// doi.org/10.1001/jama.1986.03380180126034)

11 Raff H, Auchus RJ, Findling JW \& Nieman LK. Urine free cortisol in the diagnosis of Cushing's syndrome: is it worth doing and, if so, how? Journal of Clinical Endocrinology and Metabolism 2015100 395-397. (https://doi.org/10.1210/jc.2014-3766)

12 Aranda G, Careaga M, Hanzu FA, Patrascioiu I, Rios P, Mora M, Morales-Romero B, Jimenez W, Halperin I \& Casals G. Accuracy of immunoassay and mass spectrometry urinary free cortisol in the diagnosis of Cushing's syndrome. Pituitary 201619 496-502. (https://doi.org/10.1007/s11102-016-0730-5)

13 Nieman LK, Biller BMK, Findling JW, Newell-Price J, Savage MO, Stewart PM \& Montori VM. The diagnosis of Cushing's syndrome: an Endocrine Society Clinical Practice Guideline. Journal of Clinical Endocrinology and Metabolism 200893 1526-1540. (https://doi. org/10.1210/jc.2008-0125)

Received 18 July 2019

Accepted 25 July 2019 